\title{
Intracerebral Microdialysis in Neurosurgery for Obsessive-Compulsive Disorder: Report of 2 Preliminary Cases
}

\author{
Sergio A. Sacchettoni ${ }^{1,2,3^{*}}$, Rafael Galera1,2, Juan F. Del Corral ${ }^{1}$, Juan P. Abud ${ }^{1}$, Aníbal Pinero1,

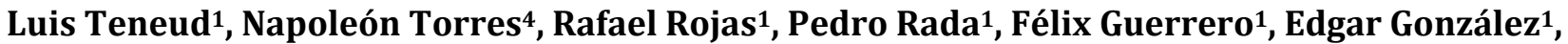 \\ Mónica Bifano' ${ }^{1}$, Dely Yazawa ${ }^{5}$, Luis Hernández ${ }^{1}$
}

${ }^{1}$ Hospital and School of Medicine JM Vargas, Universidad Central de Venezuela, Caracas, Venezuela

${ }^{2}$ Centro Medico-Docente La Trinidad, Caracas, Venezuela

${ }^{3}$ Neurology Mobile System Associates, Miami, FL, USA

${ }^{4}$ Laboratory of Physiology of Behavior, Universidad de Los Andes, Mérida, Venezuela

${ }^{5}$ University of Grenoble-Alpes, CEA, LETI, Clinatec, France

Email: *sacchettoni@gmail.com

How to cite this paper: Sacchettoni, S.A., Galera, R., Del Corral, J.F., Abud, J.P., Pinero, A., Teneud, L., Torres, N., Rojas, R., Rada, P., Guerrero, F., González, E., Bifano, M., Yazawa, D. and Hernández, L. (2020) Intracerebral Microdialysis in Neurosurgery for Obsessive-Compulsive Disorder: Report of 2 Preliminary Cases. Open Journal of Modern Neurosurgery, 10, 371-381. https://doi.org/10.4236/ojmn.2020.103040

Received: June 10, 2020

Accepted: July 12, 2020

Published: July 15, 2020

Copyright $\odot 2020$ by author(s) and Scientific Research Publishing Inc. This work is licensed under the Creative Commons Attribution International License (CC BY 4.0).

http://creativecommons.org/licenses/by/4.0/

\begin{abstract}
Neurosurgery for psychiatric disorders, notably for obsessive-compulsive disorder (OCD), was initiated in Venezuela in the decade of 1970, and consisted since that time in the classic stereotactic anterior cingulotomy. In order to know further about the physiopathology of this disorder, we performed intracerebral microdialysis in 2 patients who were operated on. The aim was to measure changes in extracellular neurotransmitters within the basal ganglia. The microdialysis probes were stereotactically placed in the right caudate nucleus and in the dorsomedial nucleus of the right thalamus. The microdialysis was done before the left cingulotomy, during the pause and after the right cingulotomy. Glutamate and gamma-aminobutyric acid (GABA) changes were similar in the caudate nucleus of both patients, whereas in the dorsomedial nucleus the changes were opposite among the 2 patients. Although this study does not bring enough data to explain such differences yet, the existence of dynamic changes in the neurochemistry of the basal ganglia during cingulotomy shows that intracerebral microdialysis can help in the understanding of the pathophysiology of OCD and eventually in the design of new surgeries with better results.
\end{abstract}

\section{Keywords}

Psychiatric Neurosurgery, Psychosurgery, Obsessive-Compulsive Disorder, Intracerebral Microdialysis 


\section{Introduction}

Neurosurgery for psychiatric diseases, particularly for obsessive-compulsive disorders (OCD), was introduced in Venezuela in the 1970s. The tradition, thus formed, of the so-called "psychosurgery" at the Vargas Hospital, was reinforced with the advent of computed tomography (CT) and resonance magnetic imaging (MRI), and it is still evolving to this day [1]. The surgery that was initially performed in Venezuela [2] [3] consisted of the bilateral stereotaxic cingulotomy described by Ballantine [4], using the Leksell stereotaxic technique [5]. Pneumoventriculography was used for the location of the target, but then, CT and MRI began to be used for this purpose [1]. Likewise, radio gamma-stereotaxic surgery was also used to produce microlesion in the anterior arm of the capsule in patients with OCD: the Leksell's capsulotomy [6].

Conservative therapies for psychiatric disorders include psychotherapy, pharmacotherapy, and electroconvulsive therapy (ECT). Fifteen to $30 \%$ of cases are refractory to therapy or have an unfavorable evolution. In these cases, neurosurgery can be presented as an acceptable alternative. OCD and affective disorders, as major depression, may benefit from surgery, especially, taking into account that some cases of OCD also develop depression. Other psychiatric pathologies, as violence-aggressiveness and self-injury-mutilation, can also be considered for surgery [7] [8] [9] [10] [11].

The following criteria are usually met for surgery. At least one year of symptoms without significant remission and 2 more years were deemed necessary to confirm the disease was refractory to the treatment. There must be an objective evaluation, by specific indicators such as the scales used in psychiatry to confirm the severity of the disease: a score of more than 20 on the Yale-Brown scale for OCD and of more than 30 on the English, Beck Depression Inventory (BDI) scale for depression. Finally, disability must be assessed and a score of less than 50 is required on the global functional assessment scale. The decision for a neurosurgical intervention should have the consensus of the involved disciplines: psychiatry/neurology and neurosurgery; and needs the agreement and consent of participation by the patient and/or their relatives/representatives. Furthermore, it is important to offer emotional support to the patient during their hospitalization and to follow a redesigned psychiatric treatment after surgery. Patients are generally adults over 18 years of age. The following examinations were performed before surgery: electroencephalogram (EEG), MRI, neuropsychological tests and independent clinical psychiatric and neurological examinations, and a routine general preoperative study [7] [8] [9].

The anatomical areas that have been most frequently chosen as targets in the various interventions in psychosurgery are the following: the dorsomedial nucleus of the thalamus (dorsomedial thalamotomy), the gyrus cinguli (cingulotomy), the anterior arm of the internal capsule (capsulotomy), lower oval center (limbic leukotomy), innominate substance (subcaudate tractotomy or subcaudotomy), tonsillar nucleus (amygdalotomy) and posterior hypothalamus or "Sano's ergotropic 
triangle" (posteromedial hypothalamotomy). The first has been used to treat anxiety in chronic pain and the last 2 have been used to treat cases of aggression. The rest of the targets have been used to treat $\mathrm{OCD}$, depression or bipolar disorder, chronic anxiety, schizophrenia, and aggression [7] [8] [9]. In this work, 2 patients were operated on the anterior cingulum.

We have currently introduced cerebral microdialysis (CMD) in humans during functional neurosurgery interventions [12] [13] [14], and in particular surgeries for OCD, with the technology developed by the Laboratory of Behavioral Physiology, University of Los Andes, Mérida, Venezuela. This team, along with that of Ungerstedt, in Sweden [15] [16], is a world pioneer in these investigations [17] [18].

The purpose of this study is to verify whether the concentrations of glutamate (Glu) and gamma-aminobutyric acid (GABA) obtained through microdialysis obtained from caudate nucleus and the dorsomedial nuclei of the thalamus, before and after cingulotomy. In the long term, this would serve as a basis to justify the use of CMD in psychosurgery operations for a better study of the pathophysiology of OCD.

\section{Patients, Materials and Methods}

The results of 2 cases operated on for obsessive-compulsive disorder are reported. One patient is a male, of 37 years old, computer engineer, suffering OCD since he was 19 years old. The other patient, female of 36 years old, public accountant, was suffering OCD since she was 15 years old. They underwent cingulotomy and cerebral microdialysis. The authorization and consent of the patients and relatives were obtained. The procedures were done according to the bioethics standards of the National Fund for Science and Technology (Fonacit) and the Institute of Biomedicine ethical rules:

(http://www.fonacit.gob.ve/documentos/bioetica2009.pdf;

http://www.biomedicina.org.ve/portal/comite-de-bioetica.html).

\section{Surgical procedure and clinical evaluations}

A stereotactic ring was placed on the patient's head (Micromar ${ }^{\circledast}$ stereotaxic system, Sao Paulo, Brasil), fixed by 4 pins to the external table of the skull. With the tomographic brain image, the distances (coordinates) between the anterior segment of each cingulum and the external references of the ring were calculated. The same was done with the caudate nucleus and the dorsomedial nucleus of the thalamus. Then, the patient was taken to the operating room and the stereotaxic arch, with the support of the electrodes, was placed.

Under aseptic and antiseptic conditions and local anesthesia, a frontal burr hole was made on each side of the frontal region and, according to the coordinates, a microdialysis cannula was advanced towards the right caudate nucleus and to the dorsal-median of the right thalamus. A pause of $30 \mathrm{~min}$ was awaited to allow the interstitial fluid to stabilize after the microtrauma caused by the introduction of the CMD probes. In Figure 1 it is shown the set up in the operating room which was used for patients' brain microdialysis. The cannulas were 


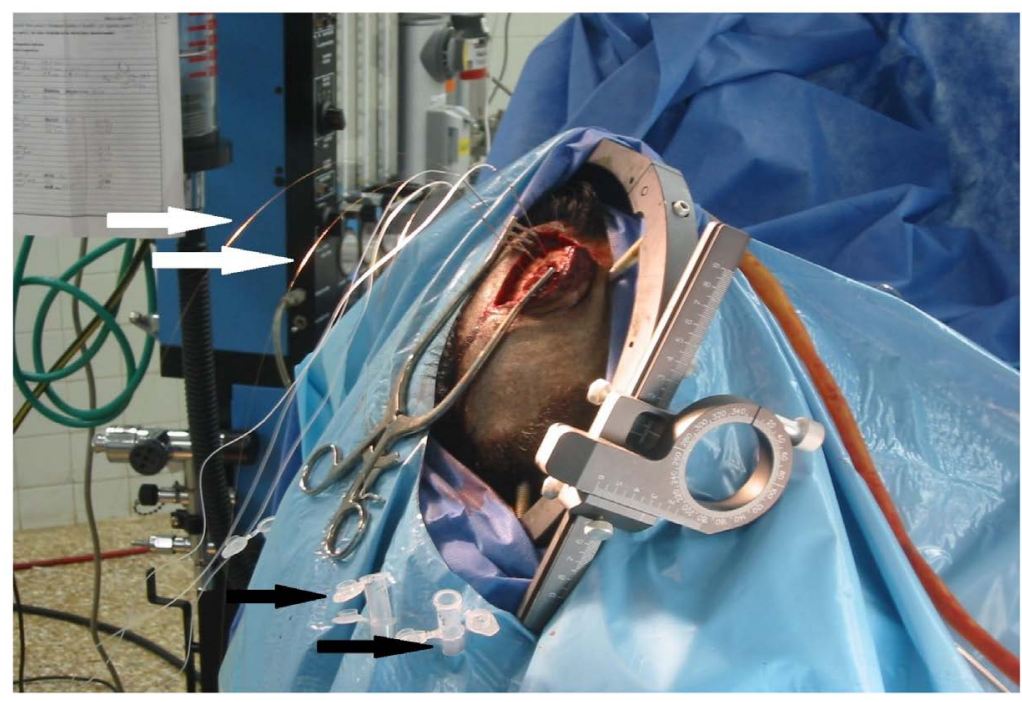

Figure 1. In the operating room, it is shown the set-up during the surgery of one patient with OCD. The microdialysis probes are placed through the burr hole. The hoses that come out of these probes (white arrows) carry the microdialysates, and are collected into the Eppendorf tubes (black arrows).

attached to the stereotaxic system by means of an adaptator manufactured by Meridialysis ${ }^{\circledast}$ (Mérida, Venezuela) (Figure 2). Finally, the monopolar electrode was advanced to the left cingulum and the microdialysis was started in the right caudate and right dorsomedial nuclei simultaneously for 5 min (sample "basal 1"). This basal microdialysis was repeated 2 more times, with 10 min interval between each one (samples "basal 2 and 3 "). Next, a $90^{\circ} \mathrm{C}$ thermocoagulation was performed for 60 seconds in the left anterior cingulum. Then, a pause of 10 min was awaited and another CMD was performed (sample "pause 1"). The electrode was removed and introduced into the right cingulum. After the right cingulotomy and a last pause of $10 \mathrm{~min}$, a last CMD was performed for a further 10 min (sample "pause 2"). The surgery ends with the removal of the electrode and the CMD probes, and the closure of the wounds. The patient is taken to their room, and observed for 3 days, during which time a postoperative brain computed tomography is prescribed in order to verify the correct location of the thermolesion in the cingulum on each side.

For the purposes of this work, the assessment was done using the Yale \& Brown scale ( $\mathrm{Y} \& \mathrm{~B}$ ) score to measure the outcome of the anterior cingulotomy on OCD [19]. It was performed 3 times during 6 months before surgery, and 2 or 3 times in 12 months post-operatively. Both patients are currently controlled with Anafranil $150 \mathrm{mg} /$ day and Risperidone $4 \mathrm{mg} /$ day.

\section{Microdialysis and sample analysis by capillary microelectrophoresis}

To obtain micro-dialysates from the cerebral interstitial fluid, CMD probes (Meridialysis ${ }^{\circledast}$, Mérida, Venezuela) were used. They consist of a stainless steel tube, with a silicon capillary inside it, that has a $2 \mathrm{~mm}$-long membrane of cellulose (13,000 Dalton-cut pores) at one end, sealed with epoxy (see Figure 2). These probes were perfused with physiological solution $(0.9 \% \mathrm{NaCl})$ at a rate of 


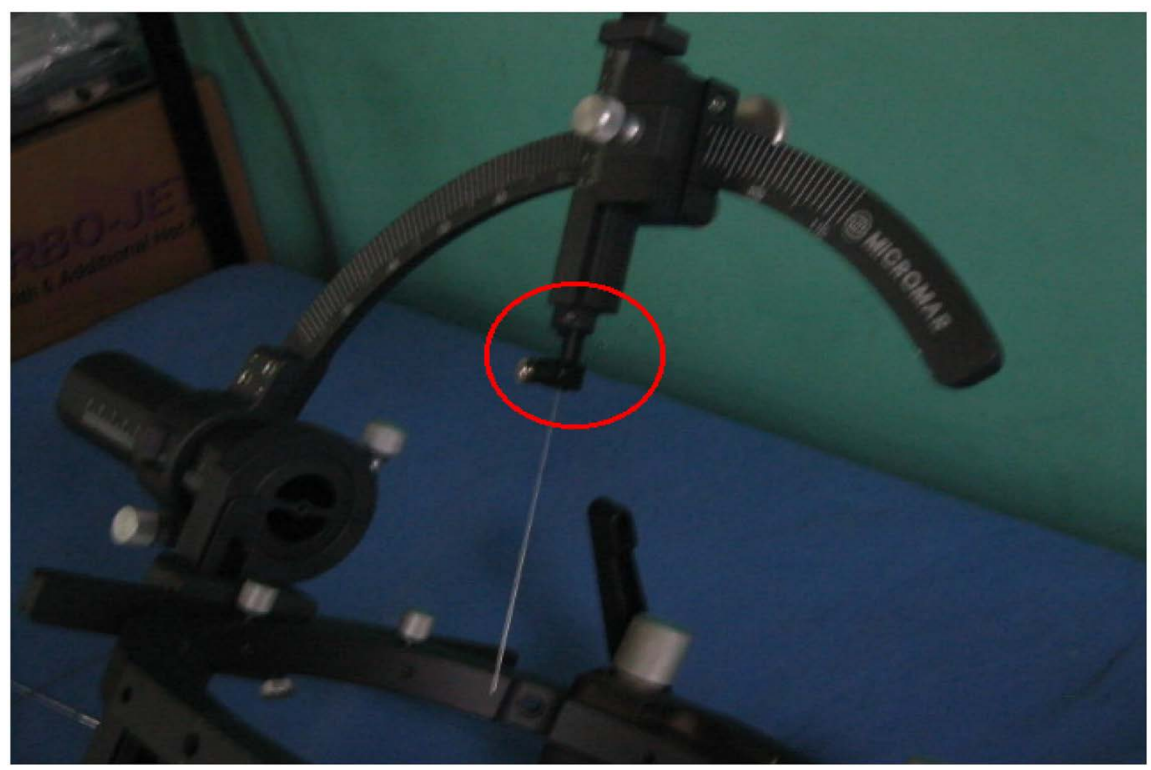

Figure 2. Adaptation manufactured by Meridialysis ${ }^{\circledast}$ that allows the microdialysis cannula to be attached to the stereotaxic system (Micromar ${ }^{\oplus}$, Sao Paulo) used for its introduction to the selected brain "target" for microdialysis.

$1 \mu \mathrm{l} / \mathrm{min}$, with a microperfusion pump. The probe drags the molecules from the cerebral interstitial fluid by concentration gradient. Because of the dialysis, the concentration inside the probe is always lower than the interstitial fluid (Figure 3). Samples were collected continuously before and after thermocoagulation.

The micro-dialysates, free of proteins, were derivatized with ninhydrin and the detection was made by capillary microelectrophoresis, with an R2D2 apparatus from Meridialysis ${ }^{\circledast}$ (Mérida, Venezuela). It has an argon laser, with a wavelength of $488 \mathrm{~nm}$, which focuses on a capillar, which internal diameter is $20 \mu \mathrm{m}$ and its length is $45 \mathrm{~cm}$. The fluorescence produced is taken to a photomultiplier that converts the light signal into voltage and this into a digital signal by an Onice ${ }^{\oplus}$ computer. The standards and the blank solution were first injected by applying a vacuum to the cathode. Then, the samples were placed on the anode and an electric current of $20 \mathrm{kV}$ was applied for $10 \mathrm{~min}$. For Glu measurement the buffer was $20 \mathrm{mM}$ carbonate/bicarbonate. For GABA measurement the buffer was $23 \mathrm{mM}$ sodium borate, $120 \mathrm{mM}$ sodium dodecyl sulfate (SDS) and $0.1 \%$ methanol. The results of the microdialysates are reported as a percentage of the initial basal absolute value, which is taken as $100 \%$.

\section{Results}

The effect of the surgery on these 2 OCD patients is illustrated in Figures 4-6, based on the Y \& B score. There was an improvement of symptoms, evidenced by the decrease in the score. The values of the microdialysis are expressed as a percentage in relation to the initial value (basal). The results showed that in the right caudate nucleus a similar behavior was obtained with GABA and with glutamate, before and after the left cingulotomy and before and after the right 


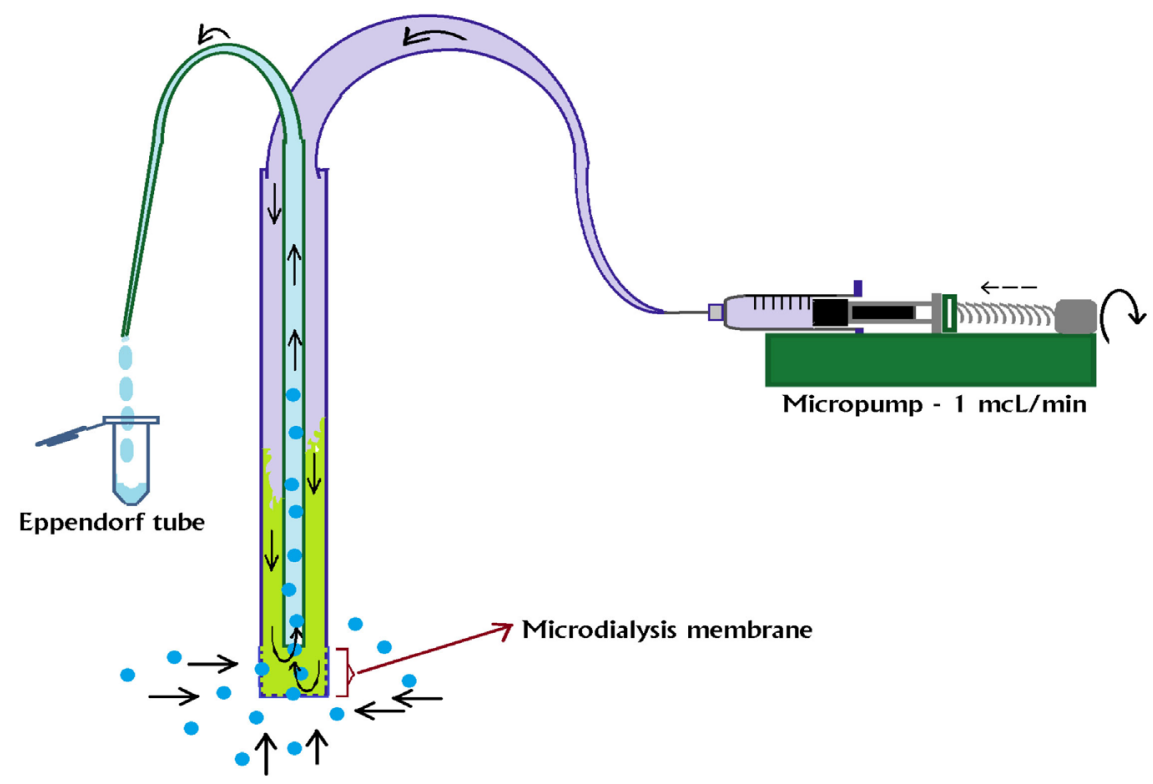

Figure 3. Diagram of the operation of a microdialysis probe. The $0.9 \%$ saline solution is injected by the microperfusion pump at a rate of $1 \mathrm{microliter} / \mathrm{min}$ and enters the cannula through the outermost concentric cylinder. When passing through the distal end, where there is the dialysis membrane of cellulose (13,000 Dalton-cut pores), it drags the molecules from the cerebral interstitial fluid, which enter by concentration gradient. Because of the dialysis, the concentration inside the probe is always lower than the interstitial fluid. The resulting dialysate leaves the cannula through the inner cylinder and is collected into Eppendorf tubes.

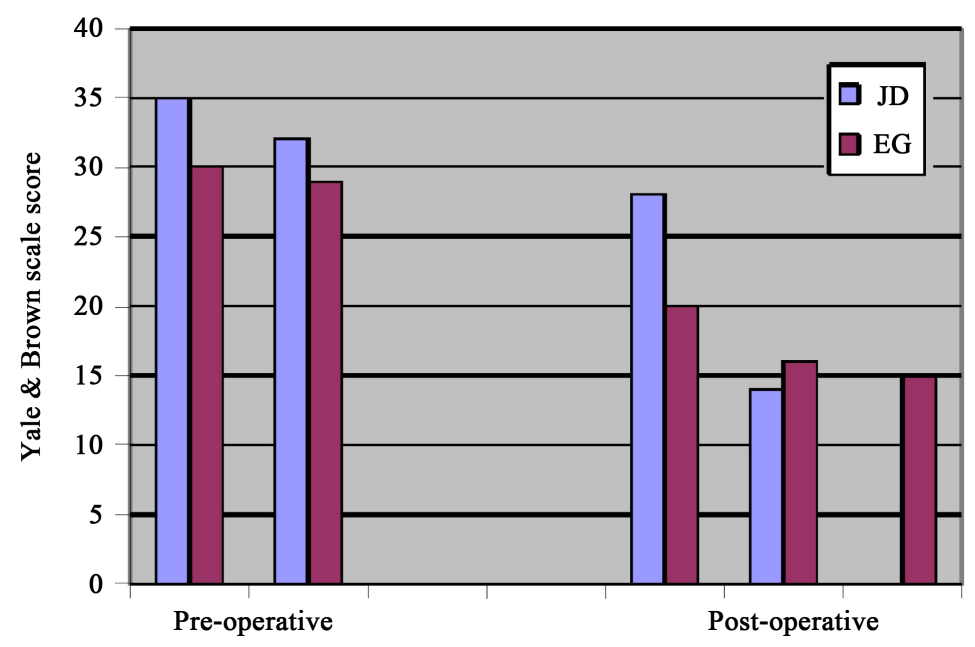

Figure 4. Pre- and post-surgical evaluation of the ODC patients using the Yale \& Brown scale score (Y \& B). The presurgical evaluations ("preoperative") were carried out over 6 months prior to the cingulotomy (axis of X 1,2). The postsurgical ("postoperative") were performed at 6, 12 and 18 months after surgery (axis of X 5, 6, 7).

cingulotomy. In the dorsomedial nucleus of the right thalamus, a completely opposite behavior of glutamate and GABA was observed for each patient. And this opposition is greater after the right cingulotomy, probably due to the greater role of this hemisphere in obsessive-compulsive disorder [20] [21] [22]. 

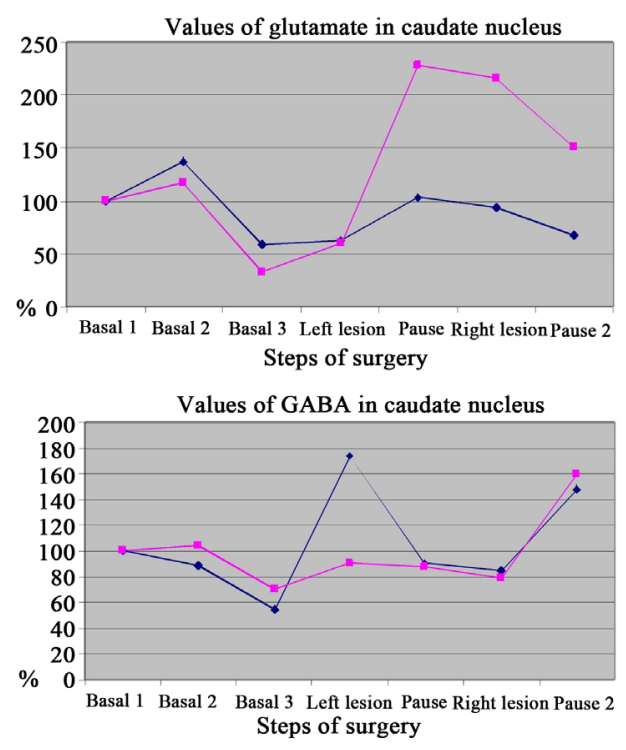

Figure 5. Values of glutamate (table above) and gamma-aminobutyric acid (GABA, table below) in the microdialysates obtained from the right caudate nucleus, from 2 patients with obsessive-compulsive disorder, who underwent stereotaxic cingulotomy (thermocoagulation radiofrequency) on the left and right sides. Microdialysis was performed before the left cingulotomy ("baseline 1, 2 and 3"), in the interim ("pause 1") and after the right cingulotomy ("pause 2"). The results of the micro dialysates are reported as a percentage of the initial basal absolute value, which is taken as $100 \%$. Note that the variations of both neurotransmitters are very similar in the 2 patients.

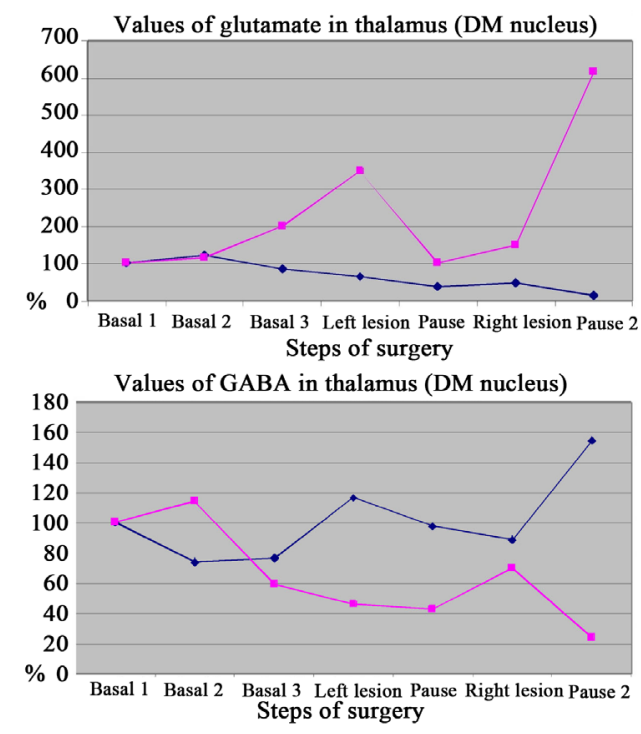

Figure 6. Glutamate (table above) and GABA (table below) values in the microdialysates obtained from the dorsomedial nucleus of the right thalamus of the 2 patients in the previous figure, with obsessive-compulsive disorder, before stereotaxic cingulotomy (radiofrequency thermocoagulation). Microdialysis was performed before the left cingulotomy ("baseline 1, 2 and 3"), in the interim ("pause 1") and after the right cingulotomy ("pause 2 "). The results of the micro dialysates are reported as a percentage of the initial basal absolute value, which is taken as $100 \%$. Here the variations do not follow the same pattern between the 2 patients, rather they are opposite, and especially after the right cingulotomy. 


\section{Discussion}

The data obtained with the use of single photon emission tomography (SPECT), positron emission tomography (PET) and functional magnetic resonance imaging (fMRI) suggest that the pathophysiology of OCD resides in the basal ganglia [23]. The proposed circuits, as a pathophysiological basis, are equivalent to those in play for Parkinson's disease and chorea: the cortico-strio-thalamus-cortical cycle [23] [24] [25] [26] [27]. In other words, motor acts, behavioral responses and ideomotricity are programmed and processed in parallel circuits with similar stations in the basal ganglia. As for the somatomotor circuit, for the ideomotor and limbic circuit, a direct route is described, from the neo-striatum (caudate nucleus and putamen and most likely the nucleus accumbens) to the globus pallidus internae (GPi), and an indirect route, which is a scale at the subthalamic nucleus (NST). From the GPi, the signals are sent to the thalamus (probably one of the main arrival nuclei is dorsomedial), where they are re-sent to the cerebral cortex.

Our results, although very preliminary, demonstrate that neurotransmitter variations do indeed occur at the beginning (caudate) of the basal ganglia circuit and at the end of it (thalamus) of these circuits. It has been described that the caudate nucleus and the thalamus play a significant role in ODC [28] [29].

With only 2 cases, it is not possible to attempt to elucidate the changes observed on the neurotransmitters detected by microdialysis, or to draw conclusions. It is interesting to note, however, that the changes reveal dynamic modifications that occur as the operation evolves and that there is also an interconnection between these structures and in both hemispheres, as noted in other publications [30] [31]. It is also worth mentioning that the greatest changes are observed after the right cingulotomy, a fact that seems to be consistent with the idea that the right hemisphere is dominant for obsessive-compulsive disorder [20] [21] [22] and probably for behavior, desire and reward in general. The perspectives offered by this novel technique are of great interest in elucidating neurochemical phenomena in OCD. The results will be very useful when confronted with future clinical studies and with new research. One of the objectives of the CMD is to verify and fine-tune the interpretations of the data obtained with non-invasive techniques (SPECT, PET and $\mathrm{fMRI}$ ) and thus to also better understand the neurochemistry and pathophysiology of ODC in order to eventually choose other intracerebral "targets" which can lead to better results for these patients.

\section{Conflicts of Interest}

The authors declare no conflicts of interest regarding the publication of this paper.

\section{References}

[1] Sacchettoni, S.A. (1991) Experiences in Stereotactic Surgery in the Vargas Hospital. Memoires of the XII Congreso Venezolano de Ciencias Médicas, Caracas, January 1991, 23-25.

[2] Del Corral, J.F. and Galera, R. (1974) Psychosurgery, First Cases in Venezuela. Acta 
Médica Venezolana, 12, 43-48.

[3] Del Corral, J.F. (1976) Stereotactic Surgery and Psychosurgery. In: The Intern Manual, Editions of the "UCV" (Central University of Venezuela), Caracas, 112-130.

[4] Ballantine Jr., H.T., Cassidy, W.L., Flanagan, N.B. and Marino Jr., R. (1967) Stereotaxic Anterior Cingulotomy for Neuropsychiatric Illness and Intractable Pain. Journal of Neurosurgery, 26, 488-495. https://doi.org/10.3171/jns.1967.26.5.0488

[5] Leksell, L. (1971) Stereotaxis and Radiosurgery: An Operative System. Charles C. Thomas, Springfield.

[6] Leksell, L. and Backlund, E.O. (1979) Stereotactic Gamma-Capsulotomy. In: Hitchcock, E.R., Ballantine, H.T. and Meyerson, B.A., Eds., Modern Concepts in Psychiatric Surgery, Elsevier North Holland Biomedical Press, Amsterdam, 213-216.

[7] Binder, D.K. and Iskandar, B.J. (2000) Modern Neurosurgery for Psychiatric Disorders. Neurosurgery, 47, 9-23. https://doi.org/10.1227/00006123-200007000-00003

[8] Lopes, A.C., de Mathis, M.A., Canteras, M.M., Salvajoli, J.V., Del Porto, J.A. and Miguel, E.C. (2004) Actualizations in the Neurosurgical Treatment of the Obsessive-Compulsive Disorder. Revista Brasileira de Psiquiatria, 26, 62-66. https://doi.org/10.1590/S1516-44462004000100015

[9] Pedrosa-Sánchez, M. and Sola, R.G. (2003) Modern Psychosurgery: A New Approach to Psychiatric Diseases. Revista de Neurología, 36, 887-897. https://doi.org/10.33588/rn.3609.2002375

[10] Paterakis, K.N., Fountas, K.N., et al. (2008) Stereotactic Amygdalotomy in the Management of Severe Aggressive Behavioral Disorders. Neurosurgical Focus, 25, E6. https://doi.org/10.3171/FOC/2008/25/7/E6

[11] Jimenez, F., Soto, J.E., Velasco, F., Andrade, P., Bustamante, J.J., Gomez, P., Ramirez, Y. and Carrillo-Ruiz, J.D. (2012) Bilateral Cingulotomy and Anterior Capsulotomy Applied to Patients with Aggressiveness. Stereotactic and Functional Neurosurgery, 90, 151-160. https://doi.org/10.1159/000336746

[12] Del Corral, J.F., Hernández, L., Sacchettoni, S.A., García, Y., Onay, D., Teneud, L. and Rada, P. (2000) Cerebral Microdialysis in Humans: Experience on Parkinson's Disease. Archivos del Hospital Vargas, 42, 93-96.

[13] Sacchettoni, S.A., Abud, J.P., Torres, N., Garcia, Y., Onay, D.A., Rodulfo, J.L., Corral, J.F.D., Rada, P., Galera, R. and Hernandez, L. (2020) Dynamic Cerebral Microdialysis during Pallidotomy and Thalamotomy in Parkinson's Disease: A Preliminary Neurochemical Study. Open Journal of Modern Neurosurgery, 10, 284-296.

https://doi.org/10.4236/ojmn.2020.102031

[14] Rada, P., Tucci, S., Teneud, L., Páez, X., Pérez, J., Alba, G., García, Y., Sacchettoni, S., Del Corral, J.F. and Hernández, L. (1999) Monitoring Gamma-Aminobutyric Acid in Human Brain and Plasma Microdialysates Using Micellar Electrokinetic Chromatography and Laser-Induced Fluorescence Detection. Journal of Chromatography B, 735, 1-10. https://doi.org/10.1016/S0378-4347(99)00386-2

[15] Ungerstedt, U. and Hallström, Å. (1987) In Vivo Microdialysis-A New Approach to the Analysis of Neurotransmitters in the Brain. Life Sciences, 41, 861-864. https://doi.org/10.1016/0024-3205(87)90181-0

[16] Meyerson, B.A., Linderoth, B., Karlsson, L. and Ungerted, U. (1990) Microdialysis in the Human Brain: Extracellular Measurements in the Thalamus of a Parkinsonian Patient. Life Sciences, 46, 301-308. https://doi.org/10.1016/0024-3205(90)90037-R

[17] Hernandez, L., Páez, X. and Hamlin, C. (1983) Neurotransmitters by Local Intracerebral 
Dialysis in Anesthetized Rats. Pharmacology Biochemistry \& Behavior, 18, 159-162. https://doi.org/10.1016/0091-3057(83)90356-8

[18] Hernandez, L., Escalona, J., Verdaguer, P. and Guzman, N.A. (1993) In Vivo Monitoring of Brain Glutamate by Microdialysis Coupled to Capillary Electrophoresis and Laser Induced Fluorescence Detection. Journal of Liquid Chromatography, 16, 2149-2160. https://doi.org/10.1080/10826079308019921

[19] Mataix-Cols, D., Fernández de la Cruz, L., Nordsletten, A.E., Lenhard, F., Isomura, K. and Blair-Simpson, H. (2016) Towards an International Expert Consensus for Defining Treatment Response, Remission, Recovery and Relapse in Obsessive-Compulsive Disorder. World Psychiatry, 15, 80-81. https://doi.org/10.1002/wps.20299

[20] Lippitz, B.E., Mindus, P., Meyerson, B.A., Kihlström, L. and Lindquist, C. (1999) Lesion Topography and Outcome Alter Thermocapsulotomy or Gamma Knife Capsulotomy for Obsessive-Compulsive Disorder: Relevance of the Right Hemisphere. Neurosurgery, 44, 452-460. https://doi.org/10.1097/00006123-199903000-00005

[21] Narayan, V.M., Narr, K.L., Phillips, O.R., Thompson, P.M., Toga, A.W. and Szeszko, P.R. (2008) Greater Regional Cortical Gray Matter Thickness in Obsessive-Compulsive Disorder. Neuroreport, 19, 1551-1555.

https://doi.org/10.1097/WNR.0b013e3283112720

[22] Hartmann, C.J., Lujan, J.L., Chaturvedi, A., Goodman, W.K., Okun, M.S., McIntyre, C.C. and Haq, I.U. (2016) Tractography Activation Patterns in Dorsolateral Prefrontal Cortex Suggest Better Clinical Responses in OCD DBS. Frontiers in Neuroscience, 9, 519. https://doi.org/10.3389/fnins.2015.00519

[23] Saxena, S. and Rauch, S.L. (2000) Functional Neuroimaging and the Neuroanatomy of Obsessive-Compulsive Disorder. Psychiatric Clinics of North America, 23, 563-586. https://doi.org/10.1016/S0193-953X(05)70181-7

[24] Alegret, M., Junqué, C., Valldeoriola, F., Vendrell, P., Martí, M.J. and Tolosa, E. (2001) Obsessive-Compulsive Symptoms in Parkinson's Disease. Journal of Neurology, Neurosurgery and Psychiatry, 70, 394-396. https://doi.org/10.1136/jnnp.70.3.394

[25] Greenberg, B.D., Murphy, D.L. and Rasmussen, S.A. (2000) Neuroanatomically Based Approaches to Obsessive-Compulsive Disorder. Neurosurgery and Transcranial Magnetic Stimulation. Psychiatric Clinics of North America, 23, 1-15. https://doi.org/10.1016/S0193-953X(05)70188-X

[26] Marino, R. and Cosgrove, G.R. (1997) Neuropsychiatry of the Basal Ganglia. Neurosurgical Treatment of Neuropsychiatric Illness. Psychiatric Clinics of North America, 20, 933-943. https://doi.org/10.1016/S0193-953X(05)70353-1

[27] Ring, H.A. and Serra-Mestres, J. (2002) Neuropsychiatry of the Basal Ganglia. Journal of Neurology, Neurosurgery and Psychiatry, 72, 12-21.

https://doi.org/10.1136/jnnp.72.1.12

[28] Huang, H., Nguyen, P.T., Schwab, N.A., Tanner, J.J., Price, C.C. and Ding, M. (2017) Mapping Dorsal and Ventral Caudate in Older Adults: Method and Validation. Frontiers in Aging Neuroscience, 9, 91. https://doi.org/10.3389/fnagi.2017.00091

[29] Rotge, J.Y., Aouizerate, B., Amestoy, V., Lambrecq, V., Langbour, N., Nguyen, T.H., Dovero, S., Cardoit, L., Tignol, J., Bioulac, B., Burbaud, P. and Guehl, D. (2012) The Associative and Limbic Thalamus in the Pathophysiology of Obsessive-Compulsive Disorder: An Experimental Study in the Monkey. Translational Psychiatry, 2, e161. https://doi.org/10.1038/tp.2012.88 
[30] Gonçalves, O.F., Carvalho, S., Leite, J., Pocinho, F., Relvas, J. and Fregni, F. (2011) Obsessive Compulsive Disorder as a Functional Interhemispheric Imbalance at the Thalamic Level. Medical Hypotheses, 77, 445-447.

https://doi.org/10.1016/j.mehy.2011.06.004

[31] Deng, K., Qi, T.F., Xu, J., Jiang, L., Zhang, F., Dai, N., Cheng, Y. and Xu, X. (2019) Reduced Interhemispheric Function Connectivity in Obsessive-Compulsive Disorder Patients. Front Psychiatry, 10, 418. https://doi.org/10.3389/fpsyt.2019.00418 